\title{
Magnetic, Surface And Elemental Characterization of FECO (50:50, 70:30) 50nm Thin Film Grown By Ultra High Vacuum DC Magnetron Sputtering on Silicon (001) Substrate
}

\author{
Mani GMK ${ }^{\mathrm{a}}$, Dhanalakshmi D ${ }^{\mathrm{a} 1}$ \\ \{ manigmk7396@gmail.com ${ }^{\mathrm{a}}$,dgd.apsc@psgtech.ac.in ${ }^{1}$ \} \\ a. Spintronics and Functional Materials Laboratory, Department of Applied Sciences, PSG College of \\ Technology, Coimbatore 641004, India. ${ }^{1}$
}

\begin{abstract}
Fe}_{50} \mathrm{Co}_{50}$ and $\mathrm{Fe}_{70} \mathrm{Co}_{30}(50 \mathrm{~nm})$ thin films prepared onto the Silicon (001) substrate at room temperature using UHV DC Magnetron Sputtering (PVD) system. We prepared FeCofilms and characterized their Magnetic, Topographic, Morphology and Elemental analysis using VSM, AFM, FESEM, and EDAX technique respectively. VSM result confirmed both materials are good magnetic in nature and both their Coercivity nearly 200Oe but $\mathrm{Fe}_{50} \mathrm{Co}_{50}$ has higher magnetization when compared to $\mathrm{Fe}_{70} \mathrm{Co}_{30}$ film. From AFM results, the average roughness and root mean Square of $\mathrm{Fe}_{50} \mathrm{Co}_{50}$ film value are double the times higher than $\mathrm{Fe}_{70} \mathrm{Co}_{30}$ film. From FESEM result Morphology of the $\mathrm{Fe}_{50} \mathrm{Co}_{50}$ film like a columnar structure and $\mathrm{Fe}_{70} \mathrm{Co}_{30}$ as like columnar agglomeration structure. EDAX result revels high number of oxygen content present in $\mathrm{Fe}_{70} \mathrm{Co}_{30}$ film than $\mathrm{Fe}_{50} \mathrm{Co}_{50}$ film as well as no other impurities present in the film.
\end{abstract}

Keywords: Magnetic thin film, FeCo, VSM, Spin polarization.

\section{Introduction}

A FeCo magnetic properties such as Coercivity, Magnetization, Retentivity depends on ratio of Fe and Co content[1]. FeCoalloy various ratios reported as65:35, 70:30, 50:50 and these magnetic thin film frequently used in magnetic sensors, Actuators, Magnetic recordings MRAM applications [2]. Past two decades spintronic communities also very interest inFeCo based thin film for Spin-valve (Spin injector) application[3, 4]. FeCo thin film used as the spin injector and spin detector in MTJ and GMR devices. Due to material magnetic property (Ferro-Magnet), 50\% of Spin Polarization and High Curie TemperatureTc-790K which is very higher than the room temperature level. $\mathrm{Fe}_{70} \mathrm{Co}_{30}(100 \mathrm{~nm})$ film has low coercivity, recorded when $500^{\circ} \mathrm{C}$ substrate temperature applied. The different morphology changedwhen substrate temperature changes. $\mathrm{Fe}_{50} \mathrm{Co}_{50}$ thin film applied to post annealing leads to change in magneticproperties. [5,6].FeCo spin injector based spin valve devices was fabricated. Bottom electrode $\mathrm{Fe}_{50} \mathrm{Co}_{50}(40 \mathrm{~nm})$ was selected as a spin injector withwork function $(4.9 \mathrm{eV})$ which was close to the organic semiconductor homo level[7]. T. Moriyama et al prepared MTJs device with $\mathrm{FeCo}$ as the spin injector and detector [8]. In this paper we discussed about the FeCo $\left(\mathrm{Fe}_{50} \mathrm{Co}_{50}, \mathrm{Fe}_{70} \mathrm{Co}_{30}\right)$ 50nm thin film Prepared onto the Si (001) substrate using UHV DC 
Magnetron Sputtering and characterized their Magnetic, Elemental, 3D-Topography and Morphology of the film studied using experimentally.

\section{Experimental Work}

Initially, the Silicon substrate cut into $1 \times 1 \mathrm{~cm}^{2}$ using a glass cutter then, immersed in ultra-sonicated Acetone, IPA and Double distilled water for removing small particles on top of the substrate surface. This cleaned Si substrate loaded into the ultra-high vacuum chamber. The UHV DC Magnetron sputtering power was fixed to $30 \mathrm{~W}$ and Argon gas flow was maintained at $7 \mathrm{Sccm}$. The base pressure and deposition pressure were $3 \times 10^{-7}$ torr and $4 \mathrm{mtorr}$, respectively. The distance between the substrate and the target was $10 \mathrm{~cm}$, Silicon Substrate was rotated at $10 \mathrm{rpm}$ as well as pre-sputtered for $10 \mathrm{mins}$. The $\mathrm{Fe}_{50} \mathrm{Co}_{50}(50 \mathrm{~nm})$ was deposited on a $\mathrm{Si}$ substrate. The thickness of the film already optimized as well as confirmed in the quartz crystal thickness monitor. Prepared FeCo thin film sample kept one day in high vacuum (base vacuum). The same conditions are maintained for $\mathrm{Fe}_{70} \mathrm{Co}_{30}$. Estimated thickness of the films was confirmed by stylus profilometer.Magnetic properties of the FeCo thin film sample was studied in VSManalysis using GMW based magnet system (GMW 3473-70). Twodimensional Morphology and elemental analysis were studied using FESEM-EDAX measurements (ZESIS instrument).3-Dimensional Topographic of the FeCo film was studied by Atomic Force Microscopy by park systems, NX20 using tapping mode operation.

\section{Result And Discussion}

Thickness of the film was confirmed by stylus profilometer shown in fig $1 \& 2$. FeCo 50 $\mathrm{nm}$ thin film was prepared but $2 \mathrm{~nm}$ higher for $\mathrm{Fe}_{70} \mathrm{Co}_{30}$ (fig.2) film which indicates oxygen involved on the surface. EDS result was also confirmed oxygen presence in the film.

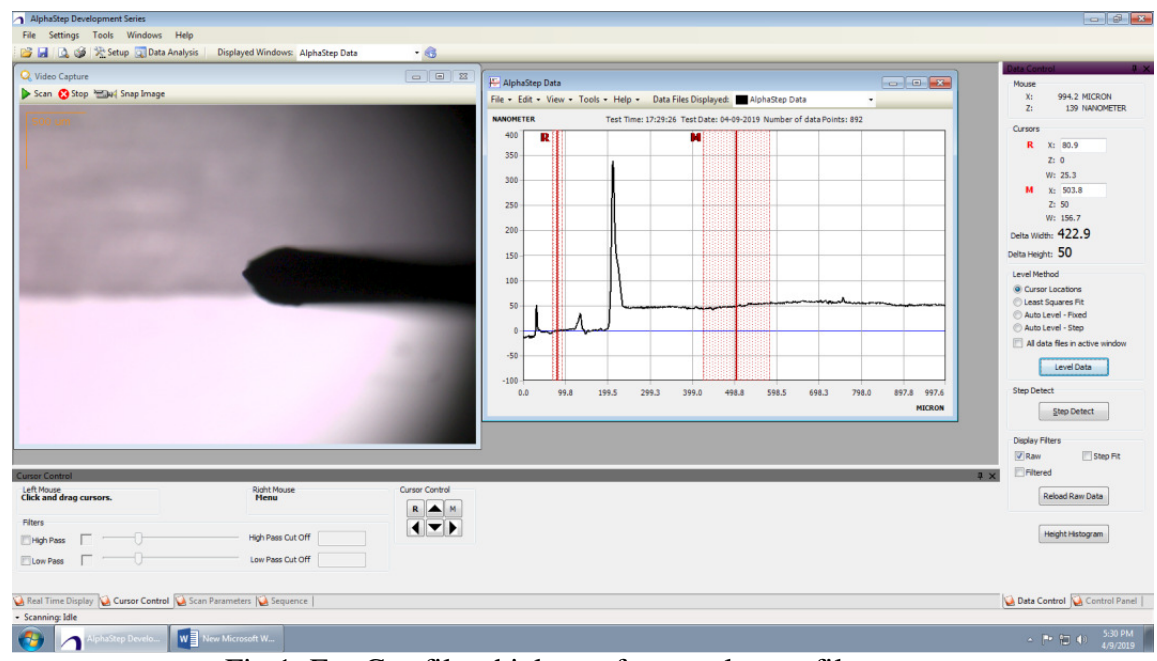

Fig 1. $\mathrm{Fe}_{50} \mathrm{Co}_{50}$ film thickness from stylus profilometer 


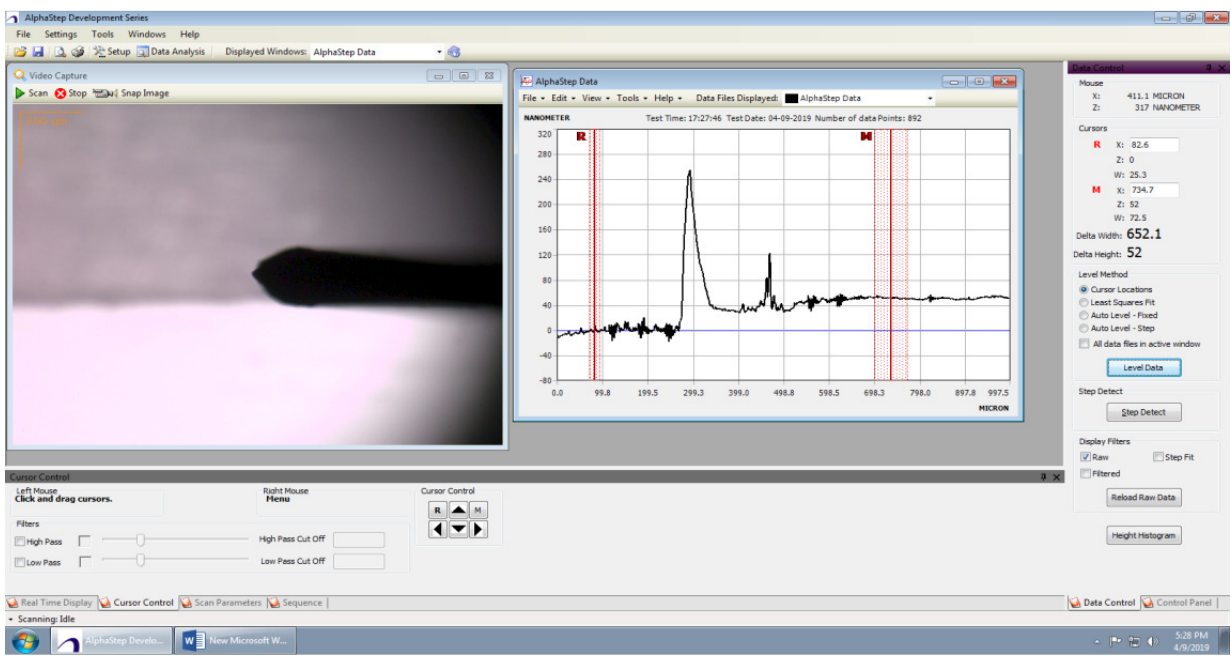

Fig 2. $\mathrm{Fe}_{70} \mathrm{Co}_{30}$ film thickness from stylus profilometer

Figure 3\&4show that EDAX result of Sputtered $\mathrm{Fe}_{70} \mathrm{Co}_{30}$ and $\mathrm{Fe}_{50} \mathrm{Co}_{50}$ thin films which contains $\mathrm{Fe}$, Co elements (sputtered elements). We confirm oxygen present in $\mathrm{Fe}_{70} \mathrm{Co}_{30}$ it may react with sample surface. Silicon peak indicates that it was a substrate material. Result also confirms no other element present in the prepared thin films. $\mathrm{Fe}_{70} \mathrm{Co}_{30}$ EDAX result (fig 3 ) also clearly indicated high number of oxygen content which may confirms that it can easily react with oxygen and might be the reason for the stability.

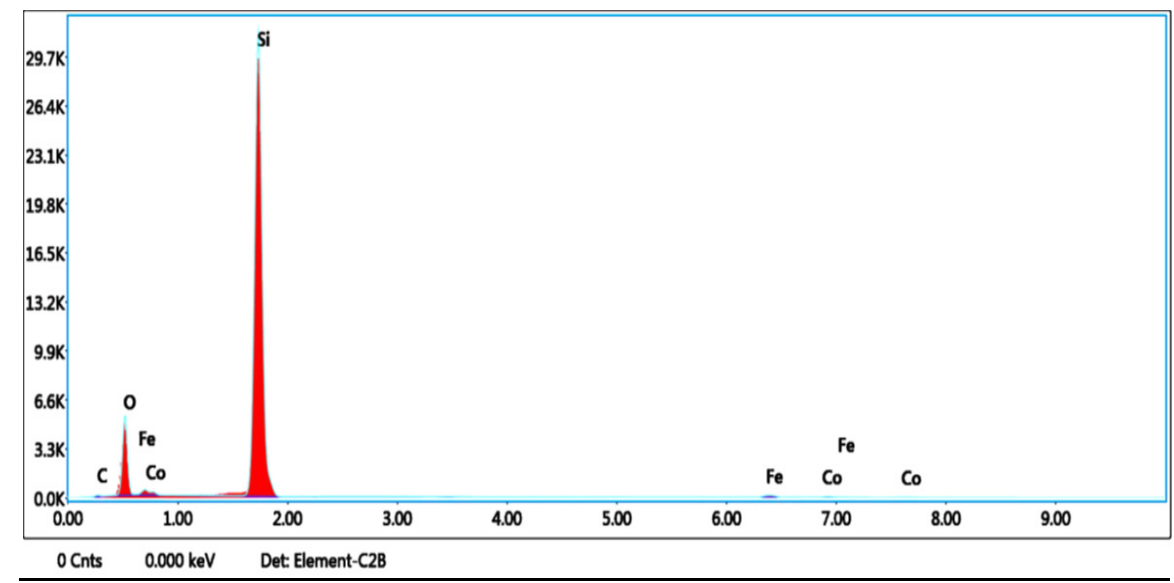

Fig 3. $\mathrm{Fe}_{70} \mathrm{Co}_{30}$ elemental analysis from EDAX result 


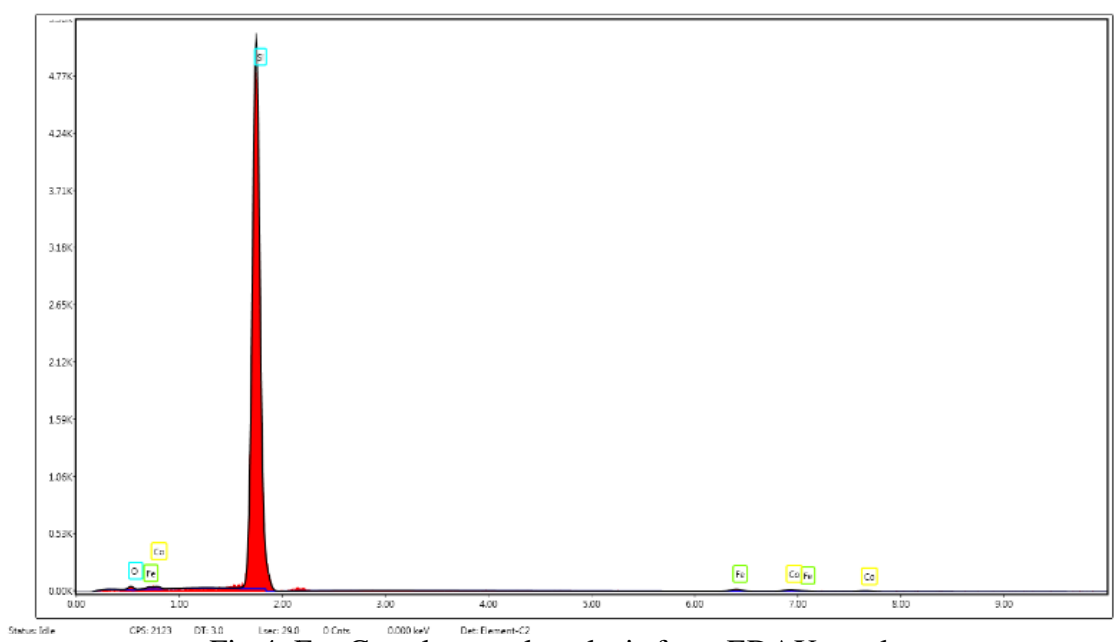

Fig 4. $\mathrm{Fe}_{50} \mathrm{Co}_{50} \mathrm{elemental}$ analysis from EDAX result

FeCo thin film morphology was studied by using the FE-SEM technique. Morphology of the FeCo (50:50, 70:30) Film like columnar structure while $\mathrm{Fe}_{70} \mathrm{Co}_{30}$ columnar agglomeration takes place due to it may easily react with oxygen shown in fig 5.From EDS result its evident of high content of oxygen presence in the $\mathrm{Fe}_{70} \mathrm{Co}_{30}$ film. Both the FeCo film morphology focusing on $100 \mathrm{~nm}$ range and $150 \mathrm{Kx}$ magnification. The images confirmed $\mathrm{Fe}_{50} \mathrm{Co}_{50} 40 \mathrm{~nm}$ film more uniform than $\mathrm{Fe}_{70} \mathrm{Co}_{30} 40 \mathrm{~nm}$ film.

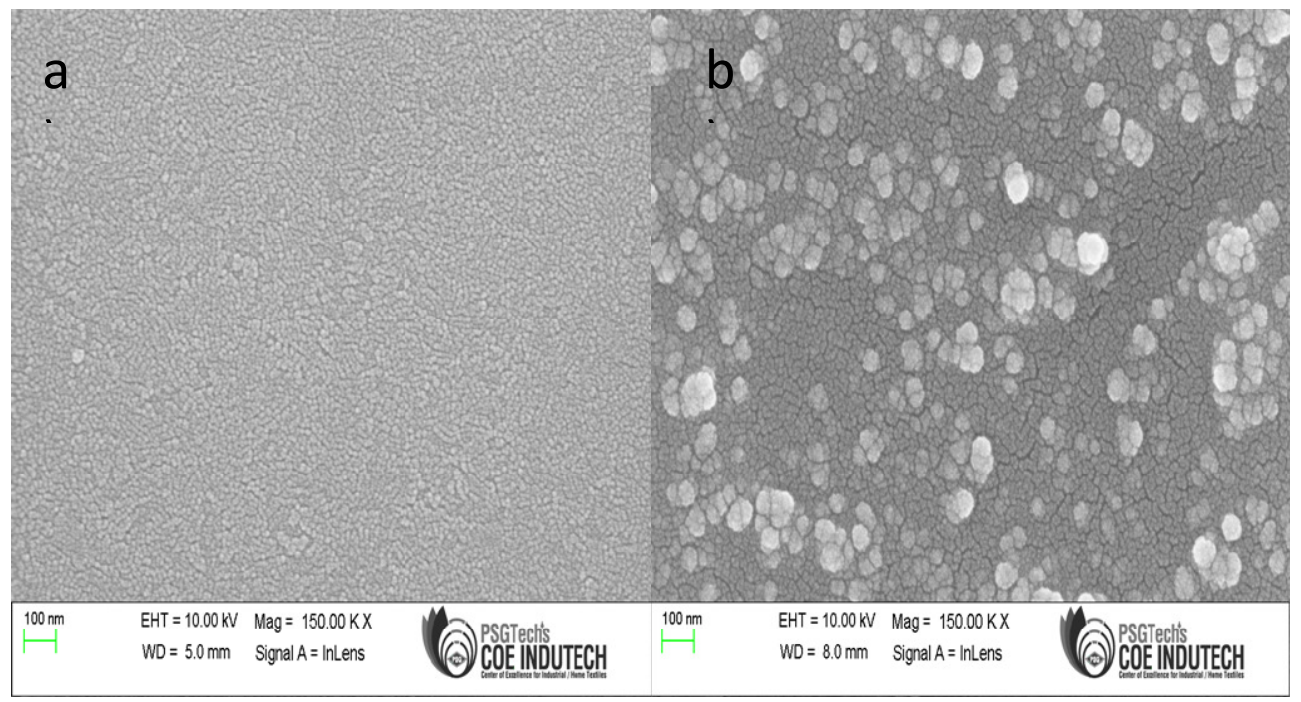

Fig 5. FESEM image of FeCo 40nm thickness . a) $\mathrm{Fe}_{50} \mathrm{Co}_{50}$ and b) $\mathrm{Fe}_{70} \mathrm{Co}_{30}$

From 3D topographical result, average roughness $(\mathrm{Ra})$ and root mean square $(\mathrm{Rq})$ was studied by AFM technique shown in fig 6 . Scanning area was done by $5 \times 5$ micrometer. The 
average roughness of $\mathrm{Fe}_{50} \mathrm{Co}_{50}$ and $\mathrm{Fe}_{70} \mathrm{Co}_{30}$ film as $1.86 \mathrm{~nm}$ and $0.68 \mathrm{~nm}$ respectively. Root mean square value as 1.98 and $0.82 \mathrm{~nm}$ respectively. $\mathrm{Fe}_{50} \mathrm{Co}_{50}$ film roughness and root mean square double the time higher the $\mathrm{Fe}_{70} \mathrm{Co}_{30}$ film roughness.

Table 1: FeCo magnetic and Surface properties

\begin{tabular}{|l|l|l|l|l|l|}
\hline $\mathrm{FeCo}$ & $\begin{array}{l}\text { Average } \\
\text { Roughness (Ra) } \\
\text { nm }\end{array}$ & $\begin{array}{l}\text { Root mean } \\
\text { Square } \\
\text { nm }\end{array}$ & $\begin{array}{l}\text { Coercivity } \\
\mathrm{Hc}(\mathrm{Oe})\end{array}$ & $\begin{array}{l}\text { Retentivity } \\
\mathrm{Mr}(\mathrm{emu} / \mathrm{cc})\end{array}$ & $\begin{array}{l}\text { Magnetization } \\
\text { Ms (emu/cc) }\end{array}$ \\
\hline $\mathrm{Fe}_{50} \mathrm{Co}_{50}$ & 1.841 & 1.968 & 214 & 143 & 159 \\
\hline $\mathrm{Fe}_{70} \mathrm{Co}_{30}$ & 0.645 & 0.816 & 206 & 185 & 202 \\
\hline
\end{tabular}
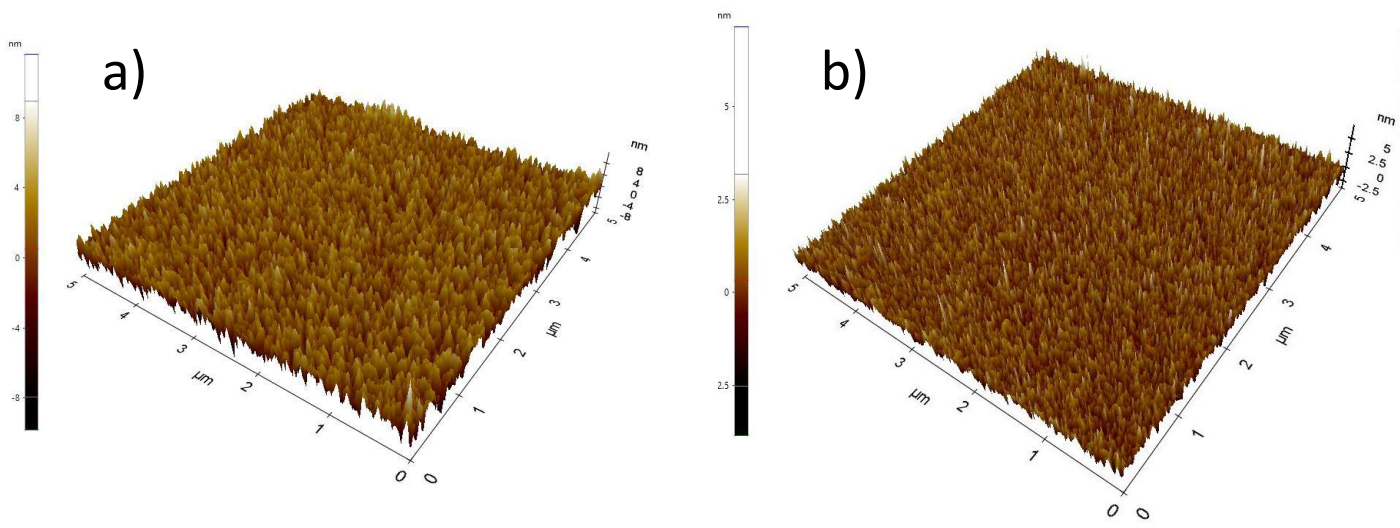

Fig 6. 3D-Topography image of FeCo 40nm thickness . a) $\mathrm{Fe}_{50} \mathrm{Co}_{50}$ and b) $\mathrm{Fe}_{70} \mathrm{Co}_{30}$

$\mathrm{FeCo}$ thin film magnetic properties were studied by VSM analysis shown inFig 7.Magnetic properties such as coercivity, saturation, andretentivity were studied using hysteresis loop. Result confirms $\mathrm{Fe}_{70} \mathrm{Co}_{30}$ and $\mathrm{Fe}_{50} \mathrm{Co}_{50}$ have magneticin nature confirmed by hysteresis loop. $\mathrm{Fe}_{50} \mathrm{Co}_{50}$ and $\mathrm{Fe}_{70} \mathrm{Co}_{30}$ Coercivity nearly same as 2140e and 2060e, respectively.Magnetization and Magnetic saturation higher for $\mathrm{Fe}_{50} \mathrm{Co}_{50}$ than $\mathrm{Fe}_{70} \mathrm{Co}_{30}$. Both FeCo look like they have the same hysteresis loop. 


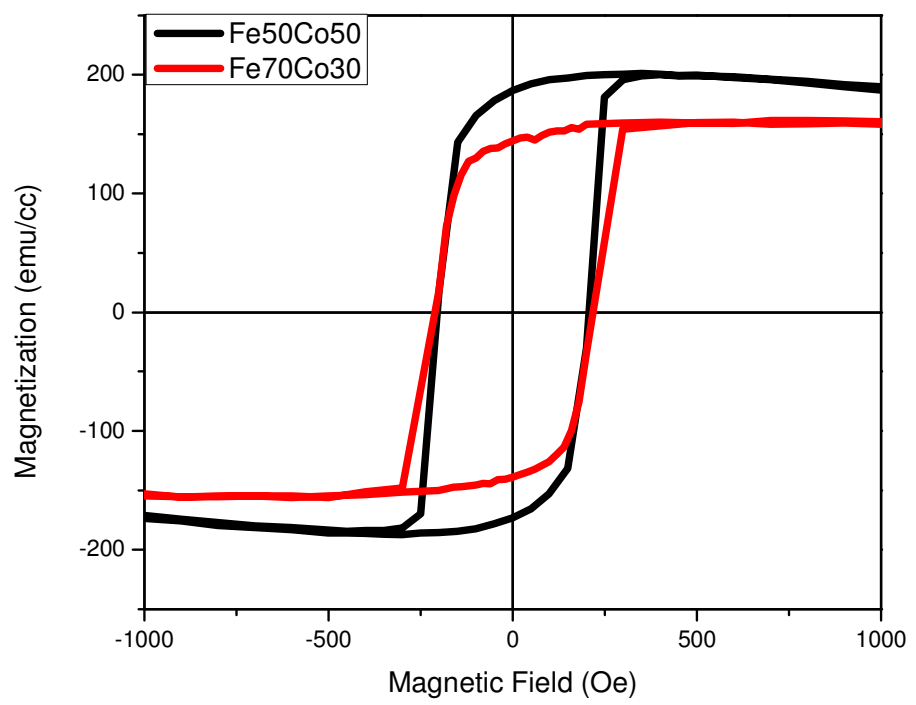

Fig 7.

Magnetic Hysteresis graph of FeCo 40nm thickness .a) $\mathrm{Fe}_{50} \mathrm{Co}_{50}$ (black) and b) $\mathrm{Fe}_{70} \mathrm{Co}_{30}$ (Red)

\section{Conclusion}

FeCowith two different ratios (50:50, 70:30) thin filmswereprepared using by UHV DC Magnetron Sputtering. Elemental analysis confirms no other element present in $\mathrm{Fe}_{50} \mathrm{Co}_{50}$ while oxygen content presents in $\mathrm{Fe}_{70} \mathrm{Co}_{30}$ it may easily react with atmospheric condition. Morphology of the film looks like similar structure. Surface roughness of the film higher for $\mathrm{Fe}_{50} \mathrm{Co}_{50}$ film and corresponding magnetization also varied. From above results it concludes, $\mathrm{Fe}_{50} \mathrm{Co}_{50}$ is a suitable electrode than $\mathrm{Fe}_{70} \mathrm{Co}_{30}$ for magnetic sensor application

\section{References}

[1] M. Abbas, M. Nazrul Islam, B. Parvatheeswara Rao, T. Ogawa, M. Takahashi, and C. Kim, "Onepot synthesis of high magnetization air-stable FeCo nanoparticles by modified polyol method," Mater. Lett., vol. 91, pp. 326-329, 2013.

[2] T. Wu et al., "Bifunctional colorimetric biosensors via regulation of the dual nanoenzyme activity of carbonized FeCo-ZIF," Sensors Actuators, B Chem., vol. 290, no. October 2018, pp. 357-363, 2019.

[3] N. A. Morley, A. Rao, D. Dhandapani, M. R. J. Gibbs, M. Grell, and T. Richardson, "Room temperature organic spintronics," J. Appl. Phys., vol. 103, no. 7, pp. 101-104, 2008.

[4] M. Bowen et al., "Large magnetoresistance in $\mathrm{Fe} / \mathrm{MgO} / \mathrm{FeCo}(001)$ epitaxial tunnel junctions on GaAs(001)," Appl. Phys. Lett., vol. 79, no. 11, pp. 1655-1657, 2001. 
[5] S. Inamdar, M. Ramudu, M. M. Raja, and S. V. Kamat, "Effect of process temperature on structure, microstructure, residual stresses and soft magnetic properties of sputtered Fe70Co30 thin films," J. Magn. Magn. Mater., vol. 418, no. April 2018, pp. 175-180, 2016.

[6] T. Prasanna Kumari, M. Manivel Raja, A. Kumar, S. Srinath, and S. V. Kamat, "Effect of thickness on structure, microstructure, residual stress and soft magnetic properties of DC sputtered Fe65Co35 soft magnetic thin films," J. Magn. Magn. Mater., vol. 365, pp. 93-99, 2014.

[7] D. Dhandapani, N.A. Morley, A. Rao, A. Das, M. Grell, M.R.J. Gibbs, Comparison of room temperature polymeric spin-valves with different organic components, IEEE Trans. Magn. 44 (2008) 2670-2673. https://doi.org/10.1109/TMAG.2008.2003060.

[8] T. Moriyama, W. Wang, J.Q. Xiao, Tunneling magnetoresistance in $\mathrm{FeCo} / \mathrm{MgO} / \mathrm{FeCo}$ tunneling junctions depending on $\mathrm{FeCo} / \mathrm{MgO}$ interface state, INTERMAG 2006 - IEEE Int. Magn. Conf. 868 (2006) 866. https://doi.org/10.1109/INTMAG.2006.374897.

[9] D. S. Vijayan, A. Mohan, J. J. Daniel, V. Gokulnath, B. Saravanan, and P. D. Kumar, "Experimental Investigation on the Ecofriendly External Wrapping of Glass Fiber Reinforced Polymer in Concrete Columns," vol. 2021, 2021.

[10] Lavanya Prabha, S., J. K. Dattatreya, and M. Neelamegam. "Investigation of bolted RPC plate under direct tension." Journal of Structural Engineering (Madras) 36.5 (2009): 333-341 